\title{
PAZ E INTERCULTURALIDAD
}

\author{
Peace and Interculturality \\ Ricardo Manrique Granados \\ Universidad de los Andes \\ ra.manrique53@uniandes.edu.co
}

Reseña de: Ramin Jahanbegloo, Paz e interculturalidad. Medellín: Colección Ediciones Universidad EAFIT, 2015, 113 págs.

Paz e interculturalidad es una compilación de siete conferencias que el filósofo iraní-canadiense, Ramin Jahanbegloo dictó en varias universidades sobre los imperativos de la paz y el pluralismo en la era de la globalización. A pesar de su relativa brevedad, el libro contiene ricos y variados argumentos con los que aborda las aproximaciones de autores como Mahatma Gandhi, Georg Hegel y Zygmunt Bauman a dichos temas: razonamientos que se enmarcan en temáticas como las estructuras del sentir y las funciones del estado, y que giran en torno de la comprensión del otro.

Al inicio de "El imperativo de la interculturalidad", primer capítulo del libro, el autor sugiere la necesidad de un cambio de paradigma en la concepción de civilización, pues esta deberá tener al diálogo como base, y no al conflicto (pp. 24-25). En ese contexto, el fin último de la civilización no sería el progreso sino que, a partir de la disposición para escuchar, comprender y responder al otro, se tendería hacia una empatía dialógica (pp. 32-33). Simultáneamente, la valoración positiva de las diferencias y el ejercicio de autoevaluaciones críticas desprovistas de sesgos permitirían el acceso a un estadio de madurez kantiana (pp. 34-35). En concordancia, Jahanbegloo evalúa un criterio de responsabilidad compatible con ello, según diferentes afirmaciones de Emmanuel Lévinas: mediante ellas rechaza la base epistemológica que sugiere la ontología; otorga prevalencia al estudio de la otredad, y enfatiza de la mano de Paul Ricoeur en la necesidad del reconocimiento de todos los miembros de la comunidad como potenciales otros (pp. 22-23).

En "El pluralismo empático" Jahanbegloo desarrolla una postura prevista en el anterior capítulo: con base en el análisis de los preceptos de Rabindranath Tagore, sugiere que el reconocimiento del pluralismo se transforma en un deber ante cualquier fórmula de monismo moral, que es entendida a su vez como un modo de vida que impone determinado régimen cultural (p. 45). En ese sentido, el autor se sirve de varias premisas de Gandhi para rechazar diversas manifestaciones de relativismo cultural, pues las asocia con divisiones culturales nocivas (p. 38). Asimismo, se opone a toda forma de nacionalismo o religiosidad por la que se dé prelación a cualquier cultura por encima de otra (pp. 46-47). 
A continuación, en "La nueva cara de la barbarie" Jahanbegloo aborda los peligros del maridaje de la globalización y el fundamentalismo en nuestra época. En consonancia, es notable el análisis que el autor hace del primero de esos fenómenos, según la noción de hombre-masa de Ortega y Gasset: concepto cuyo rasgo y paradoja esencial consiste en aspirar a los privilegios de la modernidad sin asumir la responsabilidad política que ella acarrea, lo cual conduce a la imposibilidad de derrocar las dictaduras por medio de una oposición no violenta (pp. 51-53). De ese modo, Jahanbegloo conecta los fundamentalismos religiosos y seculares pues, sustentados en lecturas arduas pero parciales de los textos que los justifican, se oponen, en igual medida, a la modernidad que los sustenta, y a las máximas del pluralismo y la convivencia de lo democrático con lo espiritual (pp. 56-58). En concordancia, el autor extiende una invitación al análisis concienzudo y pacífico de las frustraciones que acarrean el globalismo y sus ideologías (p. 61).

En "Modernidad y violencia" Jahanbegloo pone en evidencia los inconvenientes que supone la modernidad para la puesta en práctica de la democracia. Dichos impedimentos se derivan primordialmente de la racionalidad y el cientificismo propios de la época, que conllevan escisiones de todos los aspectos de la vida: atributos que en consecuencia se organizan caóticamente cada uno por su cuenta, según sus propias normas y formas de comportamiento (p. 65). De la mano de varios postulados centrales de los corpus teóricos de Zygmunt Bauman y Norbert Elias, el autor formula análisis detallados de dichas consecuencias, y postula reflexiones pertinentes sobre nociones problemáticas de la violencia y la modernidad: así, expone cómo la agresión se asocia con un conjunto de prácticas normalizadoras las cuales fundamentan la disciplina que respalda a la ley y sus arbitrariedades.

A continuación, Jahanbegloo estudia los postulados de distintos pensadores que pusieron sus ojos en la violencia como un componente necesario para la civilización. Si Maquiavelo la consideró una parte fundamental de la política (un medio que debía ser usado en proporciones bien definidas para ser efectivo), Thomas Hobbes la contempló como un rasgo inherente a la naturaleza humana: un recurso al que se renuncia cuando se constituye un estado, que es a su vez visto como una comunidad social en la que el derecho a ella es privilegio de una autoridad poderosa o soberano. Hegel, por el contrario, ve a la comunidad política ante todo como un colectivo ético; sin embargo, según su orden de pensamiento, esta entidad no solo sigue requiriendo de la agresión para sostenerse, sino que le es esencial: "la guerra es para Hegel un momento de la vida ética del estado" (p. 70). Así, aunque Hegel y Freud pertenecieran a vertientes de pensamiento distintas y difirieran en muchas de sus concepciones teóricas, según Jahanbegloo comparten una visión común de la violencia, pues la conciben como un impulso inherente a la naturaleza humana: una pulsión que debe desfogarse en la guerra para evitar la pérdida de la cordura (p. 73). En tanto, Walter Benjamin y Georges Sorel verían la violencia revolucionaria del proletariado como un medio para la creación y la preservación de la ley; pero nada impide a Jahanbegloo reafirmar que todo tipo de agresión es indeseable: aspecto según el cual se destaca el cierre del cuarto capítulo, que sirve para reflexionar sobre los usos del terrorismo. 
En consonancia, "Cosmopolitismo y diversidad: una reflexión sobre la paz democrática" gira en torno del imperativo kantiano de la superación del estado de naturaleza hobbesiano, y aborda la transición hacia un orden legal cosmopolita que garantice una paz perpetua. Así, Jahanbegloo se dedica a estudiar un inventario de circunstancias y factores -tales como el nacionalismo y la globalización- que han alejado a la humanidad del surgimiento de un espacio democrático común. Según el autor, diversos intentos de corrección de dichas contingencias, como las filosofías posideológicas y los optimismos posnacionalistas, tuvieron consecuencias tan nefastas como los genocidios de Ruanda y de los países conformados tras la disolución de Yugoslavia (p. 80). En tanto, la aparición de terrorismos híbridos que afectaron la vida en comunidad estaría ligada a un desfase conceptual según el cual la función de la democracia es la conservación de relaciones de seguridad (p. 81). En contraste, el caso de Córdoba le sirve al autor como un ejemplo de armonía diversificada: un caso que demuestra cómo el catolicismo y el islam han podido convivir desde épocas remotas y conformar comunidades caracterizadas por la superposición de creencias, aunque no por la homogeneización. En suma, este capítulo apunta hacia la necesidad de un estado de derecho supranacional capaz de balancear fines y medios para garantizar, no la seguridad, sino una condición de paz sostenible y permanente.

En el sexto capítulo del libro, "Democracia y no-violencia", Jahanbegloo explora la naturaleza paradójica de la democracia pues, si bien conlleva un grado de bienestar generalizado, en la práctica tiene a la violencia como uno de sus componentes esenciales. De ese modo, el autor reconoce que en la actualidad el ejercicio de la democracia no se debería limitar al respeto de las elecciones de las mayorías, sino que requiere actos políticos profundos tales como asumir una cierta responsabilidad ante el devenir político: una postura que llevaría a pensar en la democracia como una práctica de pensamiento y de juicio moral (p. 94).

El último capítulo del libro, "Una perspectiva no violenta de la paz", retoma los vínculos existentes entre la multiculturalidad y la paz que Jahanbegloo ha formulado previamente. En ese sentido, el autor se remite a Erasmo de Rotterdam, al teólogo español Francisco de Vitoria, a Immanuel Kant nuevamente, y al diplomático suizo Emmerich de Vattel como pensadores para quienes -hechas las salvedades que suponen las singularidades de sus líneas de estudio- el cosmopolitismo se perfiló en igual medida como una vía propicia para la fundamentación de la paz. Según lo anterior, la modernidad política condiciona toda posibilidad de que la ley se perfile como un mecanismo ideado para el ejercicio de la libertad, y no como un mecanismo de coerción comunal. De ello se deriva la remisión de Jahanbegloo a Gandhi y a su concepción de la no violencia, que coincide simultáneamente con un método para el surgimiento de una verdad ontológica y con una disposición para la autorrealización, en sintonía con la toma de conciencia de sí mismo; escenario en el que la ley se subordinaría a los ciudadanos y no los ciudadanos a la ley, y a ellos incumbiría la responsabilidad política de que ética, política y religión convergieran con el fin de superar la imagen moderna del estado (pp. 104-105). En suma, Gandhi privilegia una concepción de civilización alterna a la de la civilización moderna, y reconoce a la empatía como la máxima que orienta todo esfuerzo humano por vincularse con el otro y comprenderlo verdaderamente (pp. 106-107): funda una ciuda- 
danía no violenta, pacífica, pluralista y socialmente activa, que trasciende las separaciones tradicionales dadas entre Oriente y Occidente.

Además de construir paralelamente un tratado y un conjunto de ensayos articulados, lúcidos y bien documentados, el autor hace un aporte teórico esencial al estudio de la paz y de las figuras de intelectuales que la han abordado históricamente, según una óptica que trasciende las separaciones hemisféricas. Aunque el libro carece en esta edición de marcos críticos e hilos discursivos que permitan establecer lazos con imaginarios, prácticas y teorías asentadas en Colombia -precisamente una cualidad pertinente para el lugar de publicación y un rasgo su prologuista, Jorge Giraldo Ramírez, enfatiza-, los esfuerzos de Jahanbegloo reunidos en esta obra se perfilan como un conjunto de ejercicios académicos originales, valiosos y laudables en su prosa y amplitud. 